\title{
Molecular Analysis of Desmoid Tumors with a High-Density Single-Nucleotide Polymorphism Array Identifies New Molecular Candidate Lesions
}

\author{
Philipp Erben ${ }^{a, b *}$ Daniel Nowak ${ }^{a *}$ Christian Sauer $^{c} \quad$ Philipp Ströbel $^{c}$ \\ Wolf-Karsten Hofmann ${ }^{a} \quad$ Ralf-Dieter Hofheinz ${ }^{\mathrm{a}}$ Peter Hohenberger ${ }^{\mathrm{d}} \quad$ Bernd Kasper $^{\mathrm{d}}$ \\ ${ }^{a}$ III. Medizinische Klinik, ${ }^{b}$ Department of Urology, ${ }^{c}$ Pathologisches Institut, ${ }^{d}$ Sarkomzentrum, ITM - Interdisziplinäres Tumorzentrum, \\ Universitätsmedizin Mannheim, Ruprecht-Karls-Universität Heidelberg, Mannheim, Germany
}

\section{Keywords}

Desmoid tumors - Genomic profiling - APC .

CUB and Sushi multiple domains 1 (CSMD1)

\section{Summary}

Background: Desmoid tumors are neoplastic proliferations of connective tissues. The mutation status of the gene coding for catenin (cadherin-associated protein) beta 1 (CTNNB1) and trisomy 8 on the chromosomal level have been described to have prognostic relevance. Patients and Methods: In order to elucidate new molecular mechanisms underlying these tumors, we carried out a molecular analysis with a genome-wide human high-density single-nucleotide polymorphism (SNP) array, in 9 patients. Results: Single samples showed numerical aberrations on chromosomes (Chrs) 20 and 6 with either trisomy 20 or monosomy 6. No trisomy 8 could be detected. Recurrent heterozygous deletions were found in $\mathrm{Chr} 5 \mathrm{q}$ (including the APC gene locus, $\mathrm{n}=3$ ) and $\mathrm{Chr} 8 \mathrm{p} 23$ ( $\mathrm{n}=4$, containing coding regions for the potential tumor suppressor gene CSMD1). This novel deletion in 8 p23 showed an association with local recurrence. In addition, structural chromosomal changes (gain of Chrs 8 and 20) were found in a minority of cases. Conclusion: The genomic alteration affecting the candidate gene CSMD1 could be important in the development of desmoid tumors.

\section{Introduction}

Desmoid tumors are defined as 'clonal fibroblastic proliferations that arise in the deep soft tissues and are characterized by infiltrative growth and a tendency toward local recurrence

*These two authors contributed equally to this work.

\author{
Schlüsselwörter \\ Desmoide - Genomische Profiling-Analyse . \\ APC · CUB und Sushi multiple Domänen 1 (CSMD1)
}

\section{Zusammenfassung}

Hintergrund: Desmoide sind neoplastische Proliferationen des Bindegewebes. Für diese Tumoren wurde sowohl für den Mutationsstatus des Gens für Catenin (Cadherin-assoziiertes Protein) Beta 1 (CTNNB1) als auch für die Trisomie 8 ein prognostischer Wert beschrieben. Patienten und Methoden: Zur Evaluation neuer molekularer Mechanismen in Desmoiden haben wir für 9 Patienten humangenomische Profiling-Analysen auf der Basis eines hochauflösenden Einzelnukleotidpolymorphismen (SNP)-Arrays durchgeführt. Ergebnisse: Bei einzelnen Patienten fanden sich in den Chromosomen (Chr) 20 und 6 numerische Aberrationen mit Trisomie 20 oder Monosomie 6, aber es fand sich keine Trisomie 8. Mehrfach wurden heterozygote Deletionen in Chr 5 gefunden (inklusive des $A P C$-Lokus, $\mathrm{n}=3$ ) sowie auf $\mathrm{Chr}$ 8 p23 (enthält kodierende Abschnitte des potenziellen Tumorsuppressorgens CSMD1, $\mathrm{n}=4$ ). Diese neue Alteration zeigte einen Zusammenhang mit Lokalrezidiven. Zusätzliche strukturelle Aberrationen (Chr 8 und 20) wurden in einzelnen Fällen gefunden. Schlussfolgerung: Alterationen wie im Kandidatengen CSMD1 könnten eine wichtige Rolle in der Entwicklung von Desmoiden spielen.

but an inability to metastasize' (World Health Organization). They may affect all sites including extremities, trunk, and abdomen [1]. Two different types of desmoid tumors are described: Besides sporadic tumors there is a relationship between desmoids and familial adenomatous polyposis (FAP; Gardner syndrome) [2-4]. Here, a germ-line mutation of $A P C$ (coding for the adenomatous polyposis coli (APC) protein) predisposes patients to develop multiple colonic polyps and

\begin{tabular}{ll}
\hline KARGER & $\begin{array}{l}\text { ( ) 2012 S. Karger GmbH, Freiburg } \\
0378-584 X / 12 / 3511-0684 \$ 38.00 / 0\end{array}$ \\
$\begin{array}{l}\text { Fax +49 761 45207 14 } \\
\text { Information@Karger.de } \\
\text { www.karger.com }\end{array}$ & $\begin{array}{l}\text { Accessible online at: } \\
\text { www.karger.com/onk }\end{array}$
\end{tabular}




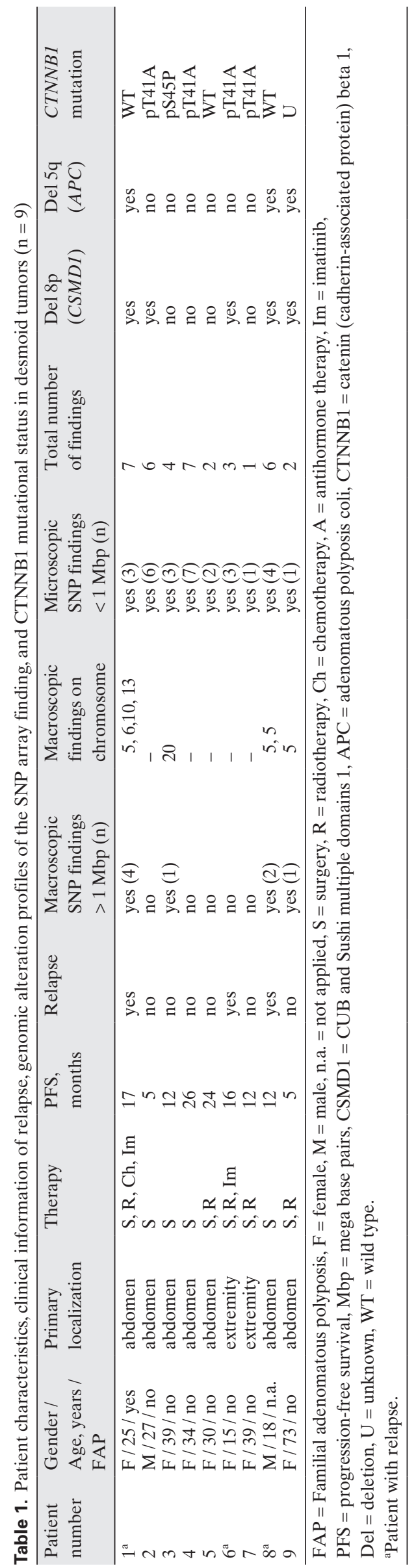

Molecular Analysis of Desmoid Tumors by SNP Array extraintestinal neoplasms such as desmoids. Besides the involvement of $A P C$ in patients with FAP - where the germline $A P C$ mutation is followed by inactivation of the wild-type $A P C$ allele - an association of the APC/beta-catenin pathway has been reported for sporadic desmoid tumors [5].

Moreover, the mutation status of the gene coding for catenin (cadherin-associated protein) beta 1 (CTNNB1) has an impact on the prognosis of patients with desmoid tumors. Recent studies indicate that at least $85 \%$ of sporadic desmoids showed mutations in this gene. Retrospectively, it was found that one of them, the S45F mutation, was the most important predictor of recurrence after surgery of the primary tumor, with a relative risk of 3.5 [6]. This represents the first documentation of a potentially clinically applicable molecular determinant of desmoids [7].

On the chromosomal level, recurrent cytogenetic alterations include trisomy 8 , trisomy 20 , and loss of chromosome (Chr) 5q. These cytogenetic alterations are described in 3-30\% of all desmoids. Most of the analyses conducted thus far were performed by conventional cytogenetics or comparative genomic hybridization (CGH) arrays. Some authors describe a prognostic impact of alterations such as trisomy 8 or Del 5q [8].

In the present pilot study, we carried out a comprehensive molecular analysis with a high-density single-nucleotide polymorphism (SNP) array in order to elucidate new molecular mechanisms underlying these rare tumors, addressing the following question: Which submicroscopic deletions could be found in desmoid tumors?

\section{Materials and Methods}

\section{Patients and Samples}

The study included 9 patients with desmoid tumors. The patient characteristics (gender, age, tumor site, treatments) are summarized in table 1. All patients were referred to our outpatient service with the diagnosis of a desmoid tumor confirmed by histology obtained from surgical specimens. Tumor specimens were classified according to the Fédération nationale des centres de lutte contre le cancer (FNCLCC) system [9]. Informed consent was obtained from all patients according to the Declaration of Helsinki. Nucleic acids were isolated from frozen surgical specimens collected at operation, after homogenization of the frozen samples using Cryoprep (Covaris, Woburn, MA, USA).

\section{SNP Array Analysis and Validation}

Genomic DNA for SNP array analyses was isolated from diagnostic tumor specimens with the ALLprep DNA/RNA kit (Qiagen, Hilden, Germany) and quality controlled by Nanodrop ND-1000 photometric measurement and evaluation by conventional agarose gel electrophoresis. $500 \mathrm{ng}$ of genomic DNA per sample was processed and hybridized according to the Genome Wide Human SNP 6.0 Array protocol instructions (Affymetrix, Santa Clara, CA, USA). Raw intensity data was processed using the Genotyping Console 4.0 software (Affymetrix). Genotyping files were imported into the CNAG 3.3 software to perform allele-specific copy number analysis as previously described [10-12], using 270 anonymous reference samples generated by the international HapMap project. Known copy number polymorphisms were excluded from the data by comparison with known copy number polymorphisms registered in the University of California Santa Cruz (UCSC) genome browser 
http://genome.ucsc.edu/. Putatively somatically acquired genomic alterations were validated on exemplary lesions by performing allele-specific copy number analysis in matched-pair SNP 6.0 array analysis of DNA from corresponding healthy tissue samples in 5 patients.
A: Chr. $5 q$

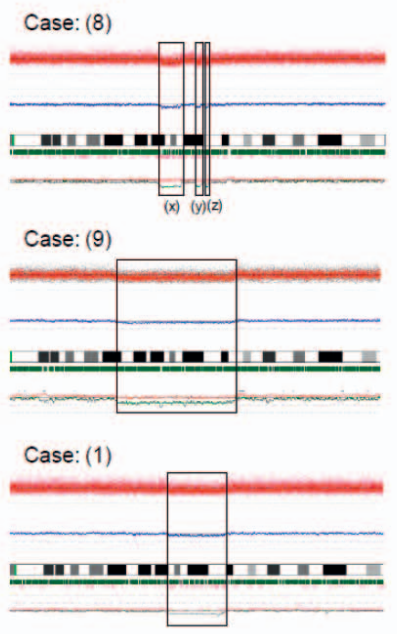

C: $\mathrm{Chr} .10$


B: Chr. $8 p 23$
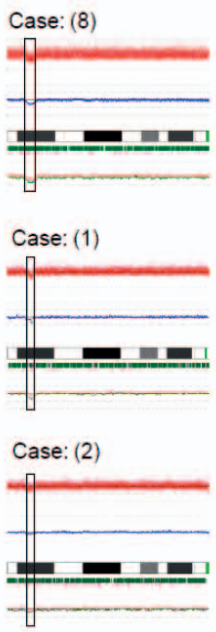

D: Validation
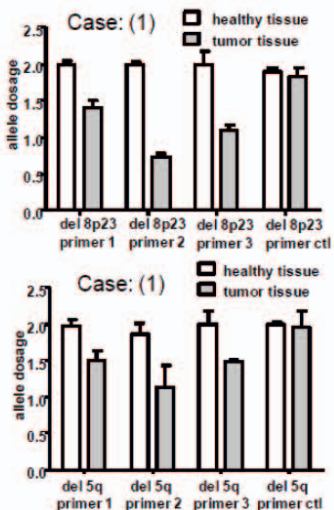

Fig. 1. Representative examples of detected genomic lesions. (A) SNP array profiles of $\mathrm{Chr} 5$ (left) displaying recurrent patterns of deletions in Chr 5 involving the $A P C$ gene. In the illustration, red dots (top panel) represent single SNP signals; the blue line indicates a smoothed average copy number. Amplifications and deletions are characterized by an up ward or downward deviation of the red dots and the blue line, respectively. In case 8 , additional small deletions, (y) and (z), could be found. These deletions contain tumor necrosis factor, alpha-induced protein 8 (TNFAIP8), and sortin nexin 2 (SNX2). (B) SNP array profile of a recurrent submicroscopic deletion that occurred in cases 1,2 and 8 , affecting the region 8p23.2 with parts of the CSMD1 gene. (C) SNP array profile of a submicroscopic deletion that occurred in cases 1 and 5 , affecting the region 10q11 with the annexin 8 gene. (D) Example of a validation set of the $5 \mathrm{q}$ and $8 \mathrm{p} 23$ deletions by quantitative real-time PCR (qRT-PCR) on genomic DNA. The deletions were validated by performing qRT-PCR on tumor samples with the deletions and compared to corresponding healthy tissue from the same patients. 3 primer pairs were located in the region of deletion (primers 1-3). White bars represent healthy tissue samples and were normalized to a copy number value of 2. Grey bars represent tumor samples and show a reduced copy number. With the control primer pair (Chr 8, Chr $5 \mathrm{ctl}$ region), which amplified regions on Chrs 5 and 8 adjacent to the corresponding deletion, both sample types showed similar copy number values.
Mutational Analysis and Gene Expression Analyses

The CTNNB1 exon 3 was amplified from genomic DNA (100 ng) using the following primers: BCATF 5'-GGTCCTCTGTGAACTTGCTC-3' and BCATR 5'-CATGTTCCATCATGGGGTCC-3'. Amplification reactions were undertaken for 35 cycles with an annealing temperature of $55^{\circ} \mathrm{C}$. The sequencing reaction was performed using the amplification primers.

In addition, mutation analyses of suspected lesions were carried out for CUB and Sushi multiple domains 1 (CSMD1) and APC by direct Sanger sequencing of genomic DNA as described for APC [13]. For CSMD1, primers were designed to amplify 500-bp-long fragments with a minimum of 30-40 bp of intronic flanking sequence or multiple overlapping sequences in the case of larger exons (primer available on request). Amplification reactions were undertaken for 32 cycles with an annealing temperature of $60{ }^{\circ} \mathrm{C}$. Polymerase chain reaction (PCR) products were analyzed by bidirectional direct sequencing using the amplification primers. Sequencing data were collected on an ABI3130 sequencer (Applied Biosytems, Foster City, CA, USA).

Genomic copy number alterations (CNAs) of Chr 8q (CSMD1) and Chr $5 \mathrm{q}$ containing the APC gene were further validated by performing SYBR green quantitative real-time PCR analysis on genomic DNA of matched healthy samples, using a Roche 480 LightCycler (Roche, Mannheim, Germany). All measurements were conducted in triplicate. Cycling program: $15 \min 95^{\circ} \mathrm{C}, 15 \mathrm{~s} 94^{\circ} \mathrm{C}, 30 \mathrm{~s} 55^{\circ} \mathrm{C}, 30 \mathrm{~s} 70{ }^{\circ} \mathrm{C}, 45$ cycles.

\section{Results}

\section{Summary of Copy Number and Recurrent Chromosomal Aberrations}

The high-density SNP array analysis of 9 desmoid samples yielded a total of 38 putatively somatically acquired genomic CNAs consisting of 15 heterozygous deletions, 23 duplications or amplifications, and no copy number neutral loss of heterozygosity (CNLOH). Overall, $100 \%$ of the patients in this cohort showed a CNA, with a median of 4 (range: 1-7; table 2, online supplemental material).

Numerical aberrations were found on Chrs 20 and 6 with either trisomy $20(\mathrm{n}=1)$ or monosomy $6(\mathrm{n}=1)$. In another patient, loss of $6 \mathrm{q}$ could be observed. Heterozygous deletions were detected on Chr 5q ( $=3)$, Chr 10p $(n=1)$ and Chr 13q $(\mathrm{n}=1)$. These macroscopic aberrations larger than $1 \mathrm{Mbp}$ (mega base pairs) could be found in $40 \%$ (4/9) of the samples (table 1).

The most common recurrent macroscopic CNAs were detected as heterozygous deletions on Chr $5 \mathrm{q}(33 \% ; \mathrm{n}=3 / 9)$ containing the $A P C$ locus (deletions ranged from 6.1 to $43 \mathrm{Mbp}$ ). From the 3 patients with this deletion, 2 showed a local recurrence after 12 and 17 months, respectively. 1 recurrence after surgery could be observed in the remaining patients (table 1).

Furthermore, a recurrent submicroscopic deletion on Chr 8p $(44 \% ; n=4 / 9)$ between 0.26 and $0.56 \mathrm{Mbp}$ was observed sharing an identical submicroscopic deletion of Chr 8p23.2 containing coding regions of CSMD1 (minimal deleted region $191 \mathrm{~kb}$; fig. 1). In 3 of 4 patients with this deletion of Chr 8p23.2, a relapse was observed after 12, 16, and 17 months, respectively (table 1). Another recurrent microdeletion affected small regions on Chr 10q11 containing regions of the annexin A8 variant (ANXA8, $n=2$ ). 
Additional submicroscopic duplications were discovered in single samples on Chrs $5 \mathrm{q}, 7 \mathrm{p}$, and $8 \mathrm{p}$. These contained the coding regions for human epidermal growth factor receptors 1 and 2 (EGFR and HER2) and RUNX1T1, the gene coding for runt-related transcription factor 1.

\section{Validation of SNP Array Data, Mutational Analysis}

Apart from changes encompassing broad genomic regions, numerous recurrent genomic microlesions smaller than $1 \mathrm{Mbp}$ could be identified (table 1). The most common recurrent microdeletion on Chr 8p23.2 (CSMD1) and the deletion of Chr 5q ( $A P C$ locus) where validated in 3 patients with corresponding healthy tissue available by performing quantitative real-time PCR on the genomic DNA to confirm the allelic loss of this region. In addition, mutation analysis of exons 4-6 of the CSMD1 gene and of the $A P C$ gene was performed and revealed no new sequence variants (fig. 1). CTNNB1 mutations where detected in $55 \%(5 / 9)$ of patients as affecting codon $41(n=4)$ and codon $45(n=1$; table 1$)$.

\section{Discussion}

Little is known about chromosomal changes in desmoid tumors. In previous studies, which performed CGH analysis and classical karyotyping, most of the desmoids were described with a normal karyotype in $50-77 \%$ of the analyzed samples [8, 14]. Using high-density SNP array analysis, our observation showed copy number changes in every single tumor. However, in $40 \%$ of our patients, aberrations larger than $1 \mathrm{Mbp}$ could be observed. Taking into account the different resolution of detection techniques such as conventional cytogenetics and CGH arrays, the results are comparable with previous studies showing that structural and numerical aberrations appeared in a subset of desmoid patients.

In a previous study, CGH loss of Chr 6 or $6 \mathrm{q}$, Chr $5 \mathrm{q}$, gain of Chr 20, and alteration of Chr $8 \mathrm{q}$ were observed with a frequency of $3-11 \%$ [8] and confirmed previous observations $[15,16]$. However, in the literature, the frequency of these aberrations is variable for the loss in Chrs $6(10-20 \%)$ and $5 q$ (5-11\%) and the gain in Chrs 8 (3-30\%) and 20 (7-30\%). In addition, a prognostic impact of trisomy 8 was suggested in 1 of these analyses. In our study, no trisomy 8 was detected. However, the small sample size and patient selection in this rare entity could explain discrepancies. In addition, the different analyses hampering comparison and the influence of culture conditions in cytogenetic studies could be proposed as other reasons. Gain of Chr 8 and Chr 20 might be overestimated because minor abnormal cell clones with trisomy 8 or 20 could have been selected for during tissue culture $[8,14]$. The losses of Chr 6 and Chr $5 q$ were comparable in the CGH and our SNP array study. However, few recurrent lesions could be observed.
In a high proportion $(30 \%)$ of patients, a deletion in Chr $5 \mathrm{q}$ was seen. This lesion contains the $A P C$ gene. Two patients with $5 \mathrm{q}$ deletion exhibited a local recurrence after 12 and 17 months, respectively. Only 1 patient without this deletion relapsed during follow-up in our cohort. However, due to the small sample size, this is observational. In a proportion of patients, desmoids are associated with FAP, and germ-line mutations in the $A P C$ gene are described $[17,18]$. In our cohort, 1 patient suffered from FAP. In desmoids, APC mutations are found between codons 1445 and 1578 [19]. Therefore, mutation analyses of the $A P C$ gene were performed but revealed no unknown sequence variant. Besides the involvement of $A P C$ in patients with FAP - where the germ-line $A P C$ mutation is followed by inactivation of the wild-type $A P C$ allele - an association of the APC/beta-catenin pathway has been reported for sporadic desmoid tumors [5].

In the literature, the frequency of CTNNB1 mutation is reported as between $50-85 \%$, and a prognostic impact is described $[6,20]$. In our series, the mutation frequency is $55 \%$. Due to the small patient cohort, no prognostic data could be reported in our series. However, none of the patients in our series was found to simultaneously have a CTNNB1 mutation and a recurrent deletion in $\mathrm{Chr} 5 \mathrm{q}$. This finding is in line with a previous analysis that alterations in $A P C$ (Del 5q) and CTNNB1 mutations do not occur simultaneously [8].

As pointed out, the development of desmoids could be linked to $A P C$ mutations and loss of $5 \mathrm{q}$, which includes the $A P C$ locus. Therefore, our findings support previous reports of the involvement of alterations of $A P C$ and the Wnt pathway, namely CTNNB1 mutations, in desmoid tumorigenesis. Apart from these known aberrations, novel submicroscopic changes were detected in our present pilot series.

The most frequent one of these alterations was a small heterozygous deletion on Chr 8p23.2 $(n=4)$ containing the coding region of CSMD1. This gene spans over $2 \mathrm{Mb}$ of genomic DNA and contains 71 exons. The gene codes for a 3565amino acid protein consisting of 14 CUB and 28 Sushi domains. CSMD1 was predicted as a receptor for unknown ligands involved in signal transduction [21]. Its gene is highly expressed in the central nervous system of rats and, in addition, it is also expressed at lower levels in areas of regenerative growth including epithelial cells of the gastrointestinal system, skin, and mammary ducts [10]. Loss of this potential tumor suppressor gene has been observed in several cancers such as prostate [22], head and neck, breast [11, 23, 24], and colon cancer. Interestingly, this lesion has not been described previously in desmoid tumors. The minimal deleted region in involved patients includes $0.26 \mathrm{Mbp}$ containing exons 4-6. Besides the deletion of this gene, point mutations and epigenetic modification leading to loss of CSMD1 transcripts have been described [11, 12, 24]. Therefore, mutational analysis was performed, but no unknown sequence variant could be detected. In addition, a prognostic impact of this loss on 8 p23 
is described in head and neck cancer and breast carcinoma $[25,26]$. Our results showed an association of this loss with local recurrence. Because of the small patient cohort, variable tumor localizations, and variable therapies, further validation is needed to investigate the role of this inactivation and its prognostic value in this rare entity.

\section{Conclusions}

We describe a comprehensive genomic profiling of DNA from patients with desmoids. In addition to the confirmed frequency of known aberrations such as $\mathrm{Chr} 5 \mathrm{q}$ deletions and CTNNB1 mutations, structural chromosomal changes (gain of Chrs 8 and 20) were found in a minority of cases. A novel recurrent deletion containing the tumor suppressor gene CSMD1, which was frequent in relapsing patients, was detected in our pilot series. Therefore, our data may help to pro- vide better insights into the molecular mechanisms underlying the development of desmoid tumors.

\section{Acknowledgements}

The authors thank Verena Nowak and Carolin Hoelting for excellent technical assistance.

\section{Disclosure Statement}

We declare that we have no conflict of interest.

\section{Online Supplementary Table}

Table 2. Summary of duplications, amplifications, and deletions found in desmoid tumor patients $(\mathrm{n}=9)$ by SNP array analysis.

To access the table, please refer to: $w w w$.karger.com/DOI $=343744$.

\section{References}

1 Biermann JS: Desmoid tumors. Curr Treat Options Oncol 2000;1:262-266.

$\checkmark 2$ Lips DJ, Barker N, Clevers H, Hennipman A: The role of APC and beta-catenin in the aetiology of aggressive fibromatosis (desmoid tumors). Eur J Surg Oncol 2009;35:3-10.

>3 Bertario L, Russo A, Sala P, Varesco L, Giarola M, Mondini P, Pierotti M, Spinelli P, Radice P: Multiple approach to the exploration of genotypephenotype correlations in familial adenomatous polyposis. J Clin Oncol 2003;21:1698-1707.

4 Clark SK, Phillips RK: Desmoids in familial adenomatous polyposis. Br J Surg 1996;83:1494-1504.

$\checkmark 5$ Gebert C, Hardes J, Kersting C, August C, Supper H, Winkelmann W, Buerger H, Gosheger G: Expression of beta-catenin and p53 are prognostic factors in deep aggressive fibromatosis. Histopathology 2007;50:491-497.

-6 Lazar AJ, Tuvin D, Hajibashi S, Habeeb S, Bolshakov S, Mayordomo-Aranda E, Warneke CL, Lopez-Terrada D, Pollock RE, Lev D: Specific mutations in the beta-catenin gene (CTNNB1) correlate with local recurrence in sporadic desmoid tumors. Am J Pathol 2008;173:1518-1527.

7 Domont J, Salas S, Lacroix L, Brouste V, Saulnier P, Terrier P, Ranchere D, Neuville A Leroux A, Guillou L, Sciot R, Collin F, Dufresne A, Blay JY, Le Cesne A, Coindre JM, Bonvalot S, Benard J: High frequency of beta-catenin heterozygous mutations in extra-abdominal fibromatosis: A potential molecular tool for disease management. Br J Cancer 2010;102:1032-1036.

8 Salas S, Chibon F, Noguchi T, Terrier P, RanchereVince D, Lagarde $\mathrm{P}$, Benard $\mathrm{J}$, Forget S, Blanchard C, Domont J, Bonvalot S, Guillou L, Leroux A, Mechine-Neuville A, Schoffski P, Lae M, Collin F, Verola O, Carbonnelle A, Vescovo L, Bui B, Brouste V, Sobol H, Aurias A, Coindre JM: Molecular characterization by array comparative genomic hybridization and DNA sequencing of 194 desmoid tumors. Genes Chromosomes Cancer 2010;49:560-568.

$\checkmark 9$ Trojani M, Contesso G, Coindre JM, Rouesse J, Bui NB, de Mascarel A, Goussot JF, David M,
Bonichon F, Lagarde C: Soft-tissue sarcomas of adults; study of pathological prognostic variables and definition of a histopathological grading system. Int J Cancer 1984;33:37-42.

10 Kraus DM, Elliott GS, Chute H, Horan T, Pfenninger KH, Sanford SD, Foster S, Scully S, Welcher AA, Holers VM: CSMD1 is a novel multiple domain complement-regulatory protein highly expressed in the central nervous system and epithelial tissues. J Immunol 2006;176:4419-4430.

11 Ma C, Quesnelle KM, Sparano A, Rao S, Park MS, Cohen MA, Wang Y, Samanta M, Kumar MS, Aziz MU, Naylor TL, Weber BL, Fakharzadeh SS, Weinstein GS, Vachani A, Feldman MD, Brose MS: Characterization CSMD1 in a large set of primary lung, head and neck, breast and skin cancer tissues. Cancer Biol Ther 2009;8:907-916.

12 Farrell C, Crimm H, Meeh P, Croshaw R, Barbar T, Vandersteenhoven JJ, Butler W, Buckhaults P: Somatic mutations to CSMD1 in colorectal adenocarcinomas. Cancer Biol Ther 2008;7:609-613.

13 Entz-Werle N, Lavaux T, Metzger N, Stoetzel C, Lasthaus C, Marec P, Kalifa C, Brugieres L, Pacquement H, Schmitt C, Tabone MD, Gentet JC, Lutz P, Babin A, Oudet P, Gaub MP, Perrin-Schmitt F: Involvement of MET/TWIST/ APC combination or the potential role of ossification factors in pediatric high-grade osteosarcoma oncogenesis. Neoplasia 2007;9:678-688.

14 Brandal P, Micci F, Bjerkehagen B, Eknaes M, Larramendy M, Lothe RA, Knuutila S, Heim S: Molecular cytogenetic characterization of desmoid tumors. Cancer Genet Cytogenet 2003;146:1-7.

15 Larramendy ML, Virolainen M, Tukiainen E, Elomaa I, Knuutila S: Chromosome band $1 \mathrm{q} 21$ is recurrently gained in desmoid tumors. Genes Chromosomes Cancer 1998;23:183-186.

16 Fletcher JA, Naeem R, Xiao S, Corson JM: Chromosome aberrations in desmoid tumors. Trisomy 8 may be a predictor of recurrence. Cancer Genet Cytogenet 1995;79:139-143.

17 Latchford A, Volikos E, Johnson V, Rogers P, Suraweera N, Tomlinson I, Phillips R, Silver A:
APC mutations in FAP-associated desmoid tumours are non-random but not 'just right'. Hum Mol Genet 2007;16:78-82.

18 Lefevre JH, Parc Y, Kerneis S, Goasguen N, Benis M, Parc R, Tiret E: Risk factors for development of desmoid tumours in familial adenomatous polyposis. Br J Surg 2008;95:1136-1139.

19 Sturt NJ, Gallagher MC, Bassett P, Philp CR, Neale KF, Tomlinson IP, Silver AR, Phillips RK: Evidence for genetic predisposition to desmoid tumours in familial adenomatous polyposis independent of the germline APC mutation. Gut 2004; 53:1832-1836.

20 Jilong Y, Jian W, Xiaoyan Z, Xiaoqiu L, Xiongzeng Z: Analysis of APC/beta-catenin genes mutations and Wnt signalling pathway in desmoidtype fibromatosis. Pathology 2007;39:319-325.

21 Sun PC, Uppaluri R, Schmidt AP, Pashia ME, Quant EC, Sunwoo JB, Gollin SM, Scholnick SB: Transcript map of the $8 \mathrm{p} 23$ putative tumor suppressor region. Genomics 2001;75:17-25.

22 Nupponen NN, Kakkola L, Koivisto P, Visakorpi T: Genetic alterations in hormonerefractory recurrent prostate carcinomas. Am J Pathol 1998;153:141-148.

23 Ishwad CS, Shuster M, Bockmuhl U, Thakker N, Shah P, Toomes C, Dixon M, Ferrell RE, Gollin SM: Frequent allelic loss and homozygous deletion in chromosome band $8 \mathrm{p} 23$ in oral cancer. Int J Cancer 1999;80:25-31.

24 Richter TM, Tong BD, Scholnick SB: Epigenetic inactivation and aberrant transcription of CSMD1 in squamous cell carcinoma cell lines. Cancer Cell Int 2005;5:29.

25 Kamal M, Shaaban AM, Zhang L, Walker C, Gray S, Thakker N, Toomes C, Speirs V, Bell SM Loss of CSMD1 expression is associated with high tumour grade and poor survival in invasive ductal breast carcinoma. Breast Cancer Res Treat 2010; 121:555-563.

26 Bockmuhl U, Ishwad CS, Ferrell RE, Gollin SM: Association of $8 \mathrm{p} 23$ deletions with poor survival in head and neck cancer. Otolaryngol Head Neck Surg 2001;124:451-455. 